\title{
Evaluation of Skin Expression Profiles in Cattle of Bos indicus and Bos taurus Lineage Following Rhipicephalus annulatus Infestation and Molecular Characterisation of S100A8 Gene
}

\author{
Elizabeth Kurian $^{1 *}$, C.N. Dinesh ${ }^{1}$, Reghu Ravindran ${ }^{2}$, Naicy Thomas ${ }^{1}$, Jain Jose ${ }^{1}$, \\ K. Raji ${ }^{3}$, K.A. Bindu ${ }^{1}$ and T.V. Aravindakshan ${ }^{1}$ \\ ${ }^{1}$ Department of Animal Breeding and Genetics, \\ ${ }^{2}$ Department of Veterinary Parasitology, ${ }^{3}$ Department of Veterinary Physiology, Kerala \\ Veterinary and Animal Sciences University, Kerala, India
}

*Corresponding author

\section{Keywords}

Tick resistance, S100A8 expression, Calprotectin, Inflammation, SNP

Article Info

Accepted:

04 June 2019

Available Online:

10 July 2019

A B S T R A C T

In tropical countries, a huge drain in profitability of animal production sector is attributed to tick and tick- borne diseases (TTBD). Traditional tick control measures are riddled by development of acaricide resistance in ticks and possibility of environmental pollution. Identifying and propagating naturally resistant breeds of cattle in endemic regions is a more efficient method in the long run. Marker assisted selection (MAS) which applies genomic information along with conventional selection in cattle breeding is a probable solution. S100A8 encodes a protein with profound pro-inflammatory, antimicrobial and antifungal activities in skin. Differential expression of the gene in the wake of Rhipicephalus annulatus infestation in Vechur a native breed of cattle in comparison to crossbred Holstein Friesian (CBHF) was studied using quantitative polymerase chain reaction (qPCR). The exons and introns of S100A8 gene were characterized in three genetic groups, Vechur, Kasargode (Bos indicus) and crossbred Holstein Friesian (Bos taurus), to identify the single nucleotide polymorphism (SNPs) present in among different populations.

\section{Introduction}

Rhipicephalus annulatus is a single host tick of cattle, endemic to the Indian subcontinent.
Huge economic losses by way of decline in production, anemia, loss of body condition, subsequent haemoparasitic infections and mortality in severe cases have been attributed 
to $R$. annulatus infestation. The Indian economy is greatly dependent on agriculture and its allied field animal husbandry is directly affected by tick and tick- borne diseases (TTBD). Control measures for TTBD even today are limited to use of topical chemical acaricides or natural repellants. But with increasing threat of harmful residues in milk and meat, soil and water pollution coupled with the emergence and rapid spread of resistant tick population it was inevitable to explore other options to control the ticks in an ecofriendly and effective manner (George et al., 2004, Li et al., 2004). Rapid strides have been made world over, with better understanding of the genetic control of the intrinsic immunological pathways of natural resistance, in identifying the key players in developing tick resistance. The genes identified in these studies can be used as markers for selecting animals which are naturally resistant to TTBD.

S100 calcium binding protein A8 (S100A8) gene encodes a small $(\sim 10.6 \mathrm{KDa})$ protein belonging to the s100 family, named such for their solubility in 100 per cent saturated solution of Ammonium sulphate.The members of this family are secreted proteins possessing two EF-hand calcium-binding motifs. Theirsub- cellular localization is in the cytoplasm and nucleus of a wide range of cells, and are involved in the regulation of multiple cellular processes such as cell cycle progression, cell differentiation and chemotaxis. Three members of S100 genes, S100A12, S100A8 and S100A9, are located as a cluster on Bovine chromosome 3 and they possess structural homology. Each has three exons and two interrupting introns - an initial

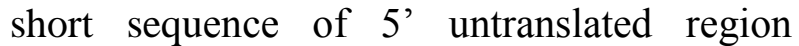
(UTR) followed by the first intron, second exon of partial 5'UTRand the coding sequence, second intron and the third exon of coding sequence and the 3'UTR (Ravasi et al., 2004). Investigations on genomic location and phylogenetic clades of $\mathrm{S} 100$ genes revealed four conserved subfamilies A2/A3/A4/A5/A6, A1/A10/A11/B/P/Z, A13/A14/A16, and $\mathrm{A} 7 \mathrm{~s} / \mathrm{A} 8 / \mathrm{A} 9 / \mathrm{A} 12 / \mathrm{G}$ indicating that these originated by tandem gene duplication (Zimmer et al., 2013). S100A8 was earlier known as migration inhibitory factor-related protein (MRP)-8, Leukocyte protein L1 light chain, cystic fibrosis antigen and calgranulin A. Although the protein was initially recognized as a unique protein of the nervous system (Moore, 1965), later studies detected its constitutive presence in neutrophils, monocytes and dendritic cells and also on stimulation in macrophages, Vascular endothelial cells, keratinocytes and fibroblasts (Edgeworth et al., 1991; Thorey et al., 2001; Hobbs et al., 2003; Grimbaldeston et al., 2003 and Rahimi et al., 2005).

While the function of S100A8and S100A9 have been identified as pro -inflammatory, the mechanism of action and different immunological pathways involved are still being explored. Ryckman et al., (2003) demonstrated that human S100A9 and S100A8 formed homodimers and heterodimer (calprotectin) in a calcium dependent manner and stimulated neutrophil chemotaxis and expression of $\beta 2$ integrin, Mac-1, resulting in neutrophil adhesion to fibrinogen. S100A8 homodimer and S100A8/A9 released by the necrotic cells as an injury or stress response points to their function as damage associated molecular pattern molecules (DAMPs).These directly bind to various cells of innate immune system with DAMP receptors like TLR4, TLR2, TLR9 resulting in intensifying the immune response by the ultimate release of cytokines and chemokines (Hermani et al., 2006; Vogl et al., 2007 and Koy et al., 2013). In 2011, Lim et al., suggested that susceptibility of S100A8 and S100A9 to oxidative modifications by various reactive oxygen species resulted in post-translational structural alterations which regulated the 
progression of inflammatory changes. Antimicrobial and antifungal properties of calprotectin could be attributed to its ability to chelate other bivalent cations such as $\mathrm{Zn}^{2+}$, $\mathrm{Mn}^{2+}$ or $\mathrm{Cu}^{2+}$, depriving the organisms of essential growth factors (Sohnle et al., 2000; Bianchi et al., 2011 and Kehl-Fie et al., 2011).

This study aims at investigating the expression profiles of the gene in Vechur and crossbred Holstein Friesian (CBHF) following artificial tick challenge and characterizing the exons and introns of $S 100 A 8$ gene from three genetic groups in Vechur, Kasargode (Bos indicus) and crossbred Holstein Friesian (Bos taurus). Vechur and Kasargode cattle are native genetic groups which have evolved and adapted to local climate and production conditions for centuries while the CBHF are progenies of selected parents with proven production potential under local conditions.

\section{Materials and Methods}

The design and nature of this experiment was approved by the CPCSEA, India (letter no. F.No.25/21/2017-CPCSEA dated 20-10-2017) and the Institutional Animal Ethics Committee (IAEC), Kerala Veterinary and Animal Sciences University.

Relative quantification of expression of S100A8

Selection of animals, sample collection and RNA isolation

Two Vechur calves and two CBHF apparently healthy male calves of six months were randomly selected from Instructional Livestock Farm Complex, College of Veterinary and Animal Sciences, Pookode for expression studies. The calves were presensitised by four cycles of artificial infestation with 20,000 Rhipicephalus (Boophilus) annulatus larvae each, 14 days apart then challenged with 10,000 larvae (da Silva et al., 2007). Skin samples for expression studies were collected from each calf just before the tick challenge and after 24 hours of tick infestation from the area where the ticks were released using $8 \mathrm{~mm}$ disposable biopsy punches (Paramount Surgimed Ltd.) avoiding previous tick attachment sites for each assay in RNAlater ${ }^{\mathrm{TM}}$ (Sigma). The collected samples were transported to the laboratory and stored at $-80^{\circ} \mathrm{C}$ freezer until RNA isolation. RNeasy Fibrous Tissue Mini kit (Qiagen) was used for isolating RNA from skin biopsies. This kit protocol provided isolation, purification and enrichment of all RNA molecules longer than 200 nucleotides from up to $30 \mathrm{mg}$ tissue. The integrity of the extracted RNA was checked using agarose gel electrophoresis. The concentration and quality of RNA was checked by NanoDrop spectrophotometer (Thermo Scientific, USA).Complementary DNA (cDNA) was synthesised from 1000ng of isolated RNA in $20 \mu \mathrm{l}$ reaction volume using RevertAid first strand cDNA synthesis kit (Thermo Scientific)as per manufacturer's protocol and stored at $-40^{\circ} \mathrm{C}$ until used.

\section{Optimization of qPCR conditions and relative quantification}

The primers for cDNA amplification of S100A8 gene by qPCR were designed and custom synthesized (Sigma Aldrich) from published bovine mRNA sequence available in GenBank (Accession no. NM_001113725.2) using Primer3 software. The primer sequence for the internal control gene GAPDH was adopted from published research article (Naicy et al., 2016). Sequences and properties of primers used for the amplification of cDNA of the genes are listed in the Table 1.

The qPCR reaction was carried out in a $10 \mu \mathrm{l}$ volume containing $5 \mu \mathrm{l}$ iTaq universal SYBR 
green super mix (BioRad), $1 \mu$ l template cDNA, $0.3 \mu \mathrm{l}$ each of forward and reverse primers $(10 \mathrm{pM} / \mu \mathrm{l})$ and $3.4 \mu \mathrm{l}$ nuclease free water. Reaction efficiency was determined by the standard curve using Illumina Eco® Q- RT PCR system. Each sample had triplicate technical replicates. The controls set for each run were, non-template control (NTC) for each gene and reverse transcription minus (RT minus) control for each cDNA sample (RNA as template), a positive control with cDNA synthesized from control RNA (provided with RevertAid first strand cDNA synthesis kit) and a negative control (with nuclease free water). The thermal profile for $\mathrm{qPCR}$ reaction and plate layout were set in the computer attached to Illumina Eco® Q- RT PCR system.

PCR reaction was set as: initial denaturation at $95^{\circ} \mathrm{C}$ for three minutes followed by 40 cycles of denaturation $\left(95^{\circ} \mathrm{C}, 20\right.$ seconds), Annealing (variable ${ }^{\circ} \mathrm{C}, 15$ seconds) and elongation $\left(72^{\circ} \mathrm{C}, 15\right.$ seconds). Dissociation (melt) curve analysis was done after each PCR. The protocol for melt curve analysis was $95^{\circ} \mathrm{C}$ for $15 \mathrm{~S}, 55^{\circ} \mathrm{C}$ for $15 \mathrm{~S}$ followed by $95^{\circ} \mathrm{C}$ for 15 $\mathrm{S}$. Data acquisition was performed during the final denaturation step. The data was analysed for relative quantification by $2^{-\Delta \Delta C} \mathrm{~T}$ method (Livak and Schmittgen, 2001).

Statistical comparison between samples was performed using ANOVA (Analysis of variance) and independent sample t-test (SPSS V.21) and subsequent Duncan's multiple range test ( $p$-value of $<0.05$ was considered statistically significant).

\section{Molecular characterisation of S100A8 gene}

Blood collection and genomic DNA isolation

Blood samples (4 $\mathrm{ml}$ each) were collected using EDTA vacutainers from 86 Vechur, 53 Kasargode and $68 \mathrm{CBHF}$ maintained at the
Vechur conservation centre at Centre for Advanced Studies in Animal Genetics and Breeding (CAS AGB), Mannuthy and farmers' herds in Thrissur, Malapuram and Wayanad districts of Kerala. Collected samples were transported to the laboratory in iceand stored at $-20^{\circ} \mathrm{C}$ until isolation of DNA. Genomic DNA was isolated using the conventional Phenol- chloroform method with modifications (Sambrook and Russell, 2001).The concentration, purity and quality of DNA samples were checked by NanoDrop spectrophotometer (Thermo Scientific, USA). The quality of the extracted genomic DNA was assessed by agarose gel ( 1 per cent W/V) electrophoresis. The gel visualized under UV trans-illuminator.

\section{Optimization of PCR conditions}

PCR was carried out to amplify fragments of S100A8 gene, from genomic DNA. In order to sequence the complete sequence of $100 \mathrm{~A} 8$ two pairs of primers were designed bovine whole genome shotgun gene sequence (GJ060612.1). The first fragment included the exon 1 with its flanking regions and the second fragment included the exons 2 and 3 with the flanking sequences (Table 2). A third PCR reaction using the forward primer of the fragment1 and the reverse sequence of fragment 2 helped to fill in the sequences between these fragments. The PCR reaction optimised was as follows $5 \mu \mathrm{l}$ Emerald Amp GT master mix (Takara), 0.3 each of forward and reverse primers, DNA template $0.5 \mu 1$ and $3.9 \mu 1$ nuclease free water. PCR cycles were optimised at initial denaturation at $95^{\circ} \mathrm{C}$ for 3 minutes followed by 35 cycles of 30 seconds denaturation at $95^{\circ} \mathrm{C}, 15$ seconds of annealing at variable temperature and 30 seconds extension at $72^{\circ} \mathrm{C}$ and finally 5 minutes final extension at $72^{\circ} \mathrm{C}$. The amplified products were checked in two per cent agarose gel electrophoresis along with $50 \mathrm{bp}$ DNA ladder (Proxi-O) 


\section{Sequence analysis}

The 10 amplicons each fromVechur, Kasargode and CBHF populations were pooled and sequenced using commercial sequencing services provided by $\mathrm{M} / \mathrm{S}$ Scigenom Labs, Kochi by Sanger dideoxy chain termination method. The chromatogram for each genetic group was observed physically for double peaks indicating single nucleotide polymorphisms (SNPs). The obtained sequences were aligned with the sequence in GenBank using BLASTn and EMBOSS: merger bioinformatic tools.

\section{PCR-RFLP analysis}

Restriction enzyme for identifying the SNP detected in the amplicons was obtained using bioinformatics tool NEB cutter version 2.0. The amplicons of S100A8 fragment 1 containing the SNP was digested with the restriction enzyme Acil (BioLabsinc.) as per the manufacturer's direction. The restriction digest was run on a $3 \%$ agarose gel at 60 volts for 60 minutes. The restriction patterns from 207 animals were genotyped under UV transilluminator and documented in gel documentation system. The allele and genotype frequencies populations of different genetic groups were calculated.

\section{Results and Discussion}

\section{S100A8 expression in Vechur (Bos indicus) and CBHF (Bos taurus)}

The amplification plot and melt curve of GAPDH and S100A8 are given in figures 1 and 2 respectively. The relative quantification of S100A8 in Vechur and CBHF is given in figure 3. There is significant 2.809-fold upregulation of the gene expression at 24 hours following the tick challenge in Vechur animals while CBHF animals, which showed no significant differential expression.

\section{Detection of SNPs and restriction fragment length polymorphism}

Chromatogram obtained from sequencing revealed a transition of thymine (T) to cytosine (C) at position 3237900 of fragment 1 amplicons of all three genetic groups while no sequence variation was noticed in chromatogram of fragment 2 amplicons (Figure 4). Acil produced a cut in strands with Cresulting in two fragments of $189 \mathrm{bp}$ and $131 \mathrm{bp}$ length respectively while the strands with $\mathrm{T}$ in the position remained uncut (Figure $5)$.

\section{Allele and genotype frequency}

The gel visualized in gel documentation system revealed that Vechur, Kasargode and CBHF animals processed either TT and TC genotypes but homozygous $\mathrm{CC}$ animals were not identified in these genetic groups. The allele and genotype frequencies are summerised in Table 3.

Kerkhof et al., (2012) indicated that wounding of the various layers of skin is the primary lesion of tick attachment which elicited a three phased response pattern by the keratinocytes and fibroblasts at the site and the infiltrating leukocytes for the effective healing process. The inflammatory phase, the proliferative phase, and the remodelling phase are orchestrated and modulated by the $\mathrm{Ca}^{2+}$ binding proteins including S100A8 and its heterodimer S100A8/A9. The initial S100A8 release is from the infiltrating neutrophils the skin which serves as a DAMP and promotes pro-inflammatory signalling, phagocytosis, oxidative burst, migration through the epithelium and clot formation. The dendritic cells and monocytes sustain the response to the next stage where there is release of inflammatory mediators which activate, propagate and regulate S100A8 release from the macrophages. 
Table.1 Sequence and properties of primers designed for PCR

\begin{tabular}{|c|l|l|c|c|c|}
\hline $\begin{array}{c}\text { Gene } \\
\text { fragment }\end{array}$ & \multicolumn{1}{|c|}{ Primer } & \multicolumn{1}{|c|}{ Primer sequence (5'-3') } & $\begin{array}{c}\text { Sequence } \\
\text { position }\end{array}$ & $\begin{array}{c}\text { Annealing } \\
\text { temperature }\end{array}$ & $\begin{array}{c}\text { Product } \\
\text { size(bp) }\end{array}$ \\
\hline $\begin{array}{c}\text { S100A8 } \\
\text { Fragment 1 }\end{array}$ & S100A8- F1 & TGAGGCTGTAGCAACACTGG & $3237712-$ & 58.7 & 320 \\
\cline { 2 - 5 } & S100A8- R1 & TGCCCTCACTCAAAAGTCCT & 3238032 & & \\
\hline $\begin{array}{c}\text { S100A8 } \\
\text { Fragment 2 }\end{array}$ & S100A8- F2 & GTAGCCATAGCCCTCTGCTG & $3238150-$ & 66.6 & 678 \\
\hline & S100A8- R2 & AAACAGAAAGCGCAATCAGG & 3238828 & & \\
\hline
\end{tabular}

Table.2 Sequence and properties of primers designed for qPCR

\begin{tabular}{|c|l|l|c|c|}
\hline \multirow{2}{*}{ Gene } & Primer & \multicolumn{1}{|c|}{ Primer sequence (5'-3') } & $\begin{array}{c}\text { Annealing } \\
\text { temperature }\end{array}$ & $\begin{array}{c}\text { Product } \\
\text { size(bp) }\end{array}$ \\
\hline \multirow{2}{*}{ GAPDH } & GAPDH-F & TGGAGAAACCTGCCAAGTATG & 60 & 127 \\
\cline { 2 - 5 } & GAPDH-R & TGAGTGTCGCTGTTGAAGTC & & \\
\hline \multirow{2}{*}{ S100A8 } & S100A8- F & CTATTTTGGGGAGACCTGGTGG & 62 & \\
\cline { 2 - 5 } & S100A8- R & TCAGGGAGTTAATGGCACACT & & \\
\hline
\end{tabular}

Table.3 Gene and genotypic frequencies for $\mathrm{T} \rightarrow \mathrm{C}$ transition at 3237900 position in target populations

\begin{tabular}{|l|l|l|l|l|l|}
\hline \multirow{2}{*}{ Genetic group } & \multicolumn{3}{|c|}{ Genotype frequencies } & \multicolumn{2}{c|}{ Gene frequencies } \\
\cline { 2 - 6 } & \multicolumn{1}{|c|}{ TT } & TC & CC & \multicolumn{2}{c|}{ T } \\
\hline Vechur (86) & $69.767(60)$ & $30.323(26)$ & $0(0)$ & 0.849 & 0.151 \\
\hline Kasargode (53) & $73.585(39)$ & $26.415(14)$ & $0(0)$ & 0.868 & 0.132 \\
\hline CBHF (68) & $92.647(63)$ & $7.353(5)$ & $0(0)$ & 0.963 & 0.037 \\
\hline
\end{tabular}

All populations were in Hardy-Weinberg Equilibrium

Number of individuals is given in parenthesis

Fig.1 A. GAPDHAmplification Plot. B.GAPDH Derivative melt curve

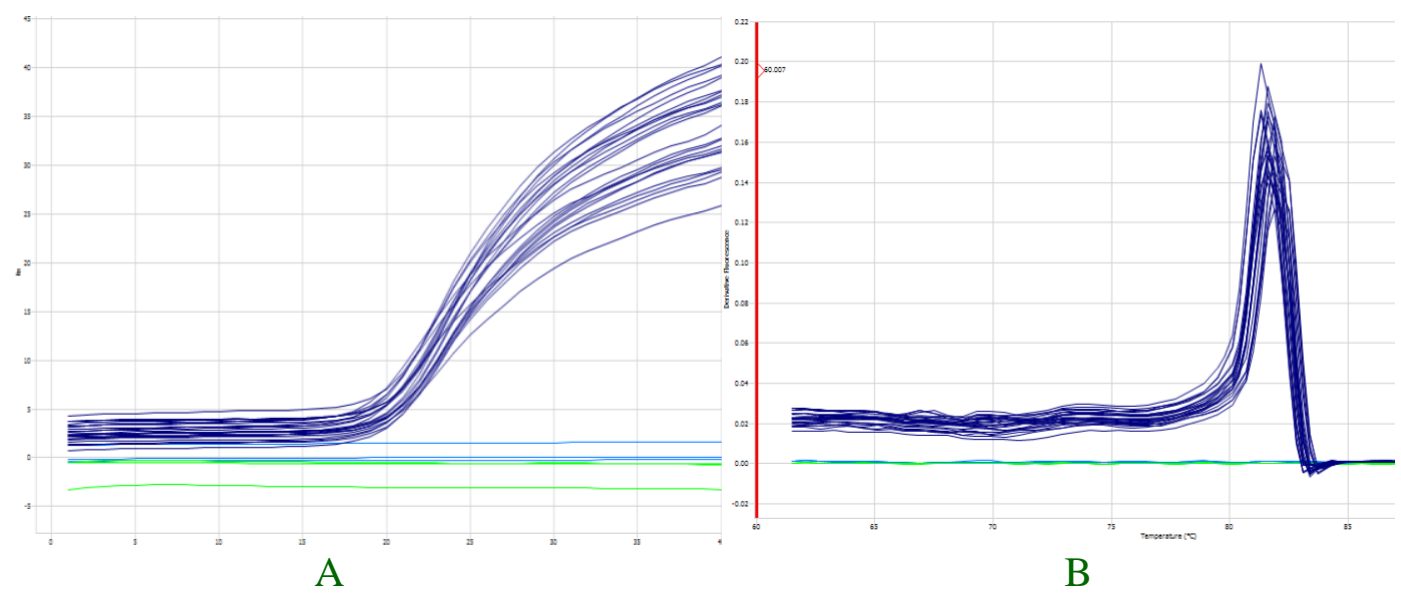


Fig.2 A. S100A8 Amplification Plot. B. S100A8 Derivative melt curve

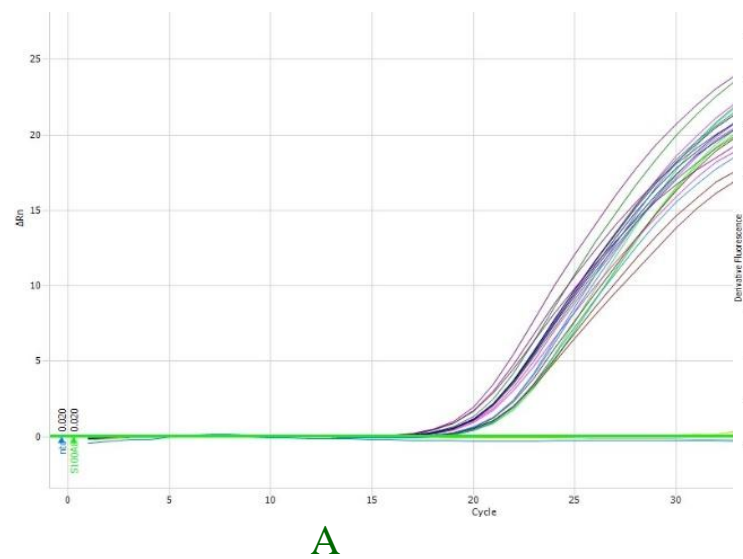

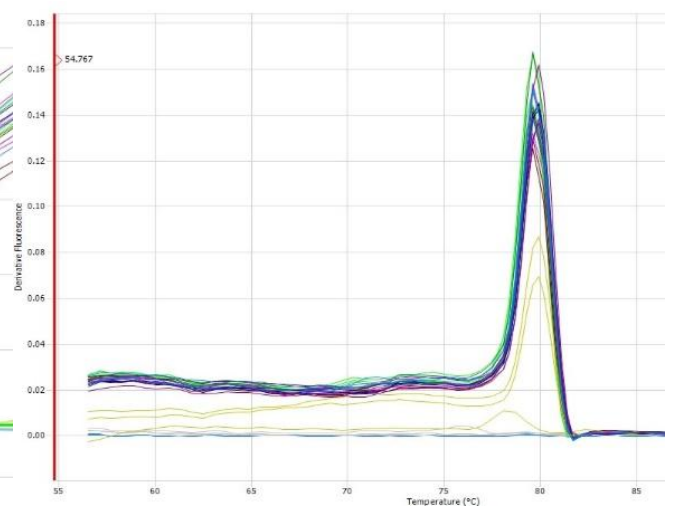

$\mathrm{B}$

Fig.3 Relative expression of S100 A8 following R. annulatus challenge

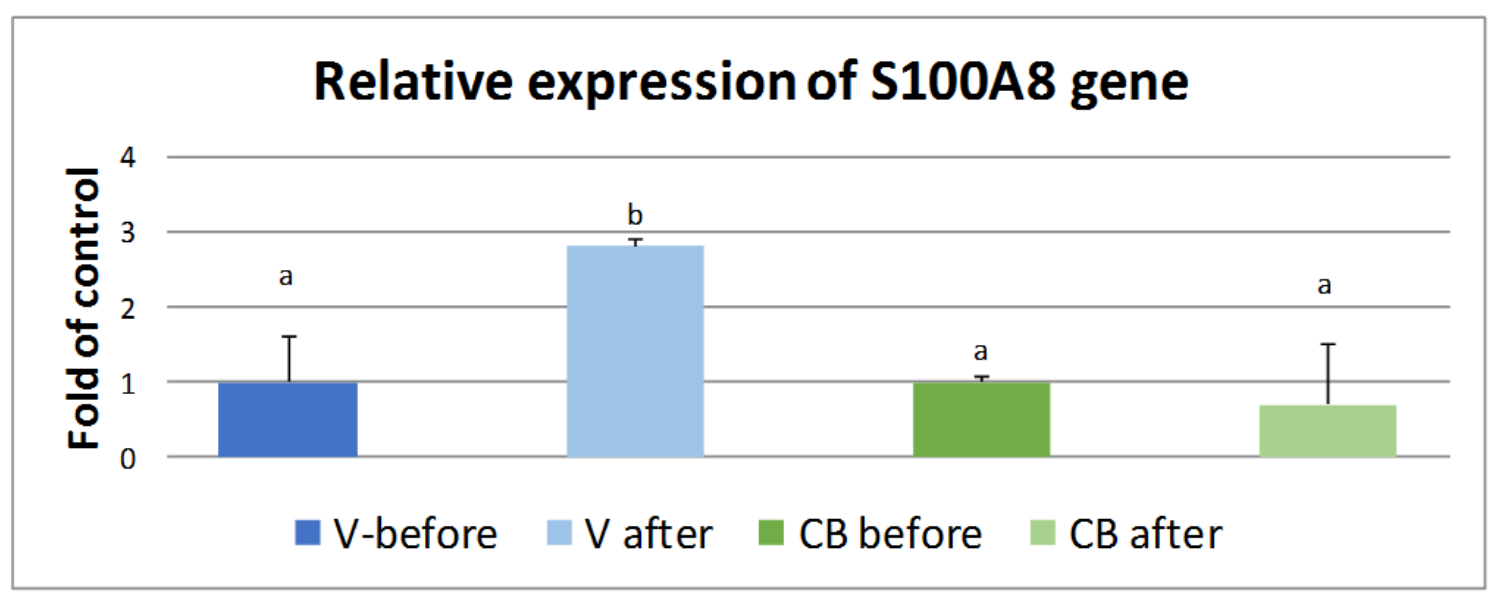

Fig.4 A. Chromatogram of homozygous uncut (TT) individual. B. Chromatogram of heterozygous (TC) individual. C. Cutting site of Acil enzyme

GGGTGGGCTG 30

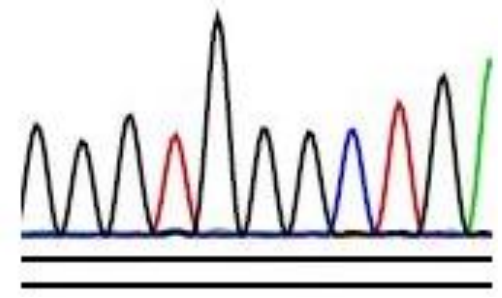

$1 \mathrm{~A}$

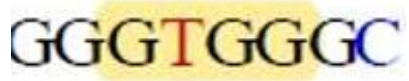

1

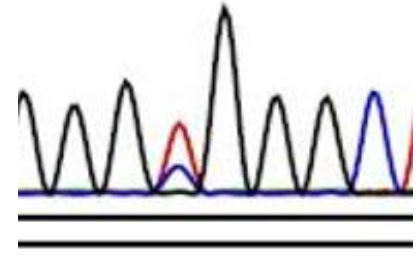

$1 \mathrm{~B}$
5 .... C'CGC ... 3

3... GGCA . . . 5

$1 \mathrm{C}$ 
Fig.5 Aci 1 RFLP patterns in S100A8 fragment 1

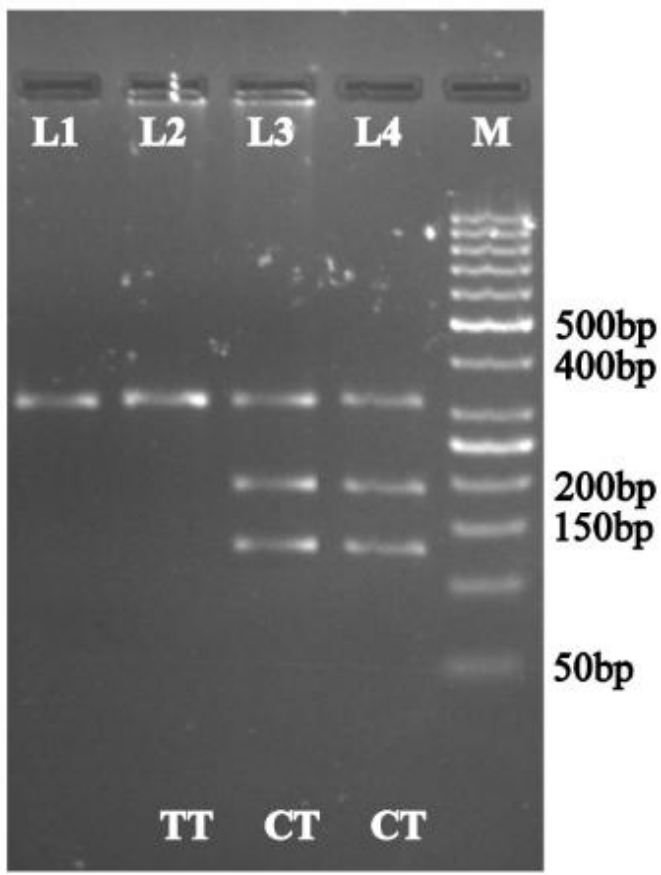

\section{Lane M : 50bp Ladder \\ Lane 1 : Amplicon of S100A8 \\ Lane 2 : Uncut RFLP product \\ Lane 3,4 : Hetrozygous RFLP product}

The inflammatory process set to motion will lead to the release of S100A8 from the keratinocytes and fibroblast during the proliferative and remodelling phases. A significant upregulation of S100A8 gene in Vechur cattle after tick challenge suggest that the initial response to the tick attachment is more rapid and immunogenic than the response elicited in the animals of Holstein Friesian lineage.

DAMP receptor TLR4 is stimulated which activates the $\mathrm{NF}_{-} \mathrm{B}$ signal pathway to induce inflammatory cytokines. Thus, elevated expression of S100A8 in Vechur animals result in inflammatory inflex, clotting of blood, thickening of skin and rapid wound resolution. This prevents the effective attachment of ticks to the host. Earlier investigations by Jonsson et al., (2014), substantiate the results from this study, the tick larvae which are unable to start feeding on attachment failed to survive. Death occurring within 24 hours of infestation could be taken as an indicator of tick resistance. Activation of TLR4 also activates a MyD88 dependent $\mathrm{T}$ helper (Th) 17 response in CD4+ T cells. These CD4+ cells belong to the adaptive immune responses. Thus, Th17 cytokines (like IL17A, IL-17F, IL-21 and IL-22) functions as link between innate and adaptive immune responses in host defence mechanism (Guglani and Khader, 2010). The T-cell-mediated response mounted by the indigenous cattle against larval stages as a response to injury at the bite site was reported to be protective.

The SNP, $\mathrm{T}$ to $\mathrm{C}$ transition identified was in intron1 of S100A8. No polymorphism could be detected within the coding sequence of the gene in the tested population. This is in 
concurrence with previous reports indigenous cattle (Kumar, 2012) and buffaloes (Sulabh et al., 2016). Kumar had however reported an A to $G$ transition at 2 bases upstream of the initiation codon in Sahiwal and Karan Fries but the population used in the study did not exhibit this polymorphism.

\section{Acknowledgment}

The authors thank the Kerala Veterinary and Animal Sciences University for the facilities provided. This research work was funded by Kerala State Council for Science, Technology and Environment under the Science Research Scheme.

\section{References}

Bagnall, N., J. Gough, L. Cadogan, B. Burns, and Kongsuwan, K., 2009. Expression of intracellular calcium signalling genes in cattle skin during tick infestation. Parasite Immunol. 31, 177-187

Bianchi, M., M. J. Niemiec, U. Siler, C. F. Urban, and Reichenbach, J., 2011. Restoration of anti-Aspergillus defense by neutrophil extracellular traps in human chronic granulomatous disease after gene therapy is calprotectin-dependent. J. Allergy Clin. Immunol. 127, 1243-1252

Da Silva, A.M., M. M. de Alencar,R. L. C. de Almeida, O. M. C. de Sena, andBarioni, W., 2007. Artificial infestation of Boophilus microplus in beef cattle heifers of four genetic groups. Genet. Mol. Biol.30, 1150-1155

Edgeworth, J., M. Gorman, R. Bennett, P. Freemont, and Hogg, N., 1991. Identification of p8, 14 as a highly abundant heterodimeric calcium binding protein complex of myeloid cells.J. Biol. Chem. 266, 7706-7713

George, J. E., J. M. Pound and Davey R. B., 2004. Chemical control of ticks on cattle and the resistance of these parasites to acaricides. Parasitology. 129 Suppl, S353- 366.

Grimbaldeston, M. A,C. L. Geczy, N. Tedla, J. J. Finlay-Jones, and Hart P. H, 2003. S100A8 induction in keratinocytes by ultraviolet $\mathrm{A}$ irradiation is dependent on reactive oxygen intermediates. J. Invest. Dermatol. 121, $1168-1174$

Guglani, L., and Khadar, S. A., 2010. Th17 cytokines in mucosal immunity and inflammation. Curr. Opin. HIV AIDS. 5, 120-127

Hermani, A., B. de Servi, S. Medunjanin, P. A. Tessier, and Mayer, D., 2006. S100A8 and S100A9 activate MAP kinase and NFkappa B signaling pathways and trigger translocation of RAGE in human prostate cancer cells. Exp. Cell. Res. 312, 184-197

Hobbs, J. A., R. May, K. Thanusis, E. McNeill, M. Mathies, C. Gebhardt, R. Henderson, M. J. Robinson, and Hogg, N.,2003. Myeloid cell function in MRP-14(S100A9) null mice. Mol. Cell. Biol. 23, 2564- 2576

Jonsson, N. N., E. K. Piper and Constantinoiu, C. C., 2014. Host resistance in cattle to infestation with the cattle tick Rhipicephalus microplus. Parasite Immunol. 36, 553-559

Kehl-Fie, T. E., S. Chitayat, M. I. Hood, S. Damo, N. Restrepo, C. Garcia, K. A. Munro, W. J. Chazin, and Skaar, E. P., 2011. Nutrient metal sequestration by calprotectin inhibits bacterial superoxide defense, enhancing neutrophil killing of Staphylococcus aureus. Cell Host Microbe. 10, 158-164

Kerkhoff, C., A. Voss, T. E. Scholzen, M. M. Averill, K. S. Zänker, and Bornfeldt, K.E., 2012. Novel insights into the role of S100A8/A9 in skin biology. Exp. Dermatol. $21,822-826$

Koy, M., N. Hambruch, J. Hussen, C. Pfarrer, H. M. Seyfert, and Schuberth, H. J., 2013. Reconmbinant bovine S100A8 and A9 enhance IL-1 secretion of interferon gamma primed monocytes. Vet. Immunol. Immunopathol.155, 162-170

Kumar, R. S., 2012. Characterisation and allele mining of Bovine FEZL and S100A8 genes and their association with mastitis in dairy cattle. Ph.D thesis. National Dairy Research Institute, Karnal (https://krishikosh.egranth.ac.in/displaybitst ream?handle $=1 / 80625$ )

Li, A.Y., R. B. Davey, R. J. Miller, and George, J.E., 2004. Detection and characterization 
ofamitraz resistance in the southern cattle tick, Boophilus microplus (Acari: Ixodidae). J. Med. Entomol. 41, 193- 200

Lim, S. Y., M. J. Raftary, and C. L. Geczy, 2011. Oxidative modifications of DAMPs suppress inflammation: The case for S100A8 and S100A9. Antioxid. Redox Signal.15, 2235-2248.

Livak, K. J. and Schmittgen, T. W., 2001. Analysis of relative gene expression data using real- time quantitative PCRand the 2 $\Delta \Delta \mathrm{C}$ T method. Methods. 25, 402- 408

Moore, B. W., 1965. A soluble protein characteristic of the nervous system. Biochem. Biophys. Res. Commun. 19,739744

Naicy, T., R. T. Venkatachalapathy, T. V. Aravindakshan, G, Radhika, K. C. Raghavan, M. Mini, and Shyma, K., 2016. Nerve Growth Factor gene ovarian expression, polymorphism identification, and association with litter size in goats. Theriogenology. 86, 2172-2178

Rahimi, F., K. Hsu, Y.Endoh, and Geczy, C. L., 2005. FGF-2, IL-1beta and TGF-beta regulate fibroblast expression of S100A8. FEBS J. 272, 2811-2827

Ravasi, T., K. Hsu, J. Goyette, K. Schroder, Z. Yang, F. Rahimi, L. P. Miranda, P. F. Alewood, D. A. Hume, and Geczy, C., 2004. Probing the S100 protein family through genomic and functional analysis. Genomics. 84, 10- 22

Ryckman, C., K. Vandal, P. Rouleau, M. Talbot, and Tessier, P. A., 2003. Proinflammatory activities of S100: proteins S100A8, S100A9, and S100A8/A9 induce neutrophil chemotaxis and adhesion. J. Immunol.170, 3233-3242

Sambrook, J. and Russell, D. W. 2001. Preparation and analysis of eukaryotic DNA. In: Molecular cloning: A laboratory manual, 3Ed. Cold Spring Harbour Laboratory Press, New York, 6.1- 6.62

Sohnle, P. G., M. J. Hunter, B. Hahn, and Chazin, W. J., 2000. Zinc reversible antimicrobial activity of recombinant calprotectin (migration inhibitory factor related protein 8 and 14). J. Infect. Dis. 182, 1272-1275

Sulabh, S., A. Verma, I. D. Gupta, and Kumar, V., 2016. Genotyping of calgranulin A gene in Murrah buffaloes by PCR- RFLP. Indian J. Dairy Sci. 69, 1-4

Thorey, S. I., J. Roth, J. Regenbogen, J. P. Halle, M. Bittner, T. Vogl, S. Kaesler, P. Bugnon, B. Reitmaier, S. Durka, A. Graf, M. Wockner, N. Rieger, A. Konstantinow, E. Wolf, A. Goppelt, Werner, S., The $\mathrm{Ca}^{2+}$ binding proteins S100A8 and S100A9 are encoded by novel injury regulated genes. J. Biol. Chem. 276, 35818-35825

Vogl, T.,K. Tenbrock, S. Ludwig, N. Leukert, C. Ehrhardt, M. A. van Zoelen, W. Nacken, D. Foell, T. van der Poll, and Sorg, C., 2007. Mrp8 and Mrp14 are endogenous activators of Toll-like receptor 4, promoting lethal, endotoxin-induced shock. Nat. Med. 13, 1042-1049

Zimmer, D. B., J. O. Eubanks, D. Ramakrishnan and Criscitiello, M. F., 2013. Evolution of the S100 family of Calcium sensor proteins. Cell Calcium. 53,170-179

\section{How to cite this article:}

Elizabeth Kurian, C.N. Dinesh, Reghu Ravindran, Naicy Thomas, Jain Jose, K. Raji, K.A. Bindu and Aravindakshan, T.V. 2019. Evaluation of Skin Expression Profiles in Cattle of Bos indicus and Bos taurus Lineage Following Rhipicephalus annulatus Infestation and Molecular Characterisation of S100A8 Gene. Int.J.Curr.Microbiol.App.Sci. 8(07): 132-141. doi: https://doi.org/10.20546/ijcmas.2019.807.017 